\title{
The study on the dimensions of dynamic capability of enterprises
}

\author{
Mingxian Wang ${ }^{1} \quad{\operatorname{Ran~} \mathbf{L i}^{2}}^{2}$ \\ ${ }^{1}$ Research Centre of Management Innovation and Evaluation, Tianjin University of \\ Commerce,wangmingxian03@126.com \\ ${ }^{2}$ TianJin university of commerce,879085901@qq.com
}

\begin{abstract}
Now dynamic capability is the focus of academic research, but the empirical research of dynamic capability is difficult to study. According to related literature, we prove that the dynamic capability including four dimensions is valid with many theoretical analysis and questionnaire survey of empirical research. Four dimensions consist of the opportunity perception, resource acquisition, organizational learning ability and integration restruction capability. This paper has a reference to operate and practice in an uncertain environment and the enterprise's strategic management.
\end{abstract}

Keywords: Dynamic capability; Constituent elements; Dimension

\section{Introduction}

With the globalization growing, the resources and competitive edge owned by the enterprise is changing with diversity. Enterprises can not grow in a stable environment, but they face the question how to adapt to survive in the dynamic and changing environment. Therefore, under this trend it is realistic significance to study the composition of the dimensions of dynamic ability. Dynamic capability is an ability to integrate, build, and restructure internal and external parts, as well as an ability to change the operation and adapt to the dynamic change. It is also the source of sustainable competitive edge in the rapidly changing environment. So we are clear that enterprises cultivate dynamic capabilities to adjust existing resources, skills, and ability is important to meet the challenges of the globalization and innovation. But the study of dynamic capability is not enough in-depth so far, and its dimensions and measurement has not been unified. Studying these problems is the vital to enterprise's survival and development as well as the formation of long-term competitive edge.

\section{Review}

The dynamic capabilities are hard to be verified, but scholars can explore and research from different angles. So combing previous theory and literature, we think that enterprise's dynamic capabilities can be composed by opportunity perception, resource acquisition capability, organizational learning capability and restruction capability. These four aspects respectively refer to the ability to insight opportunity in changed environment, to acquire new resources, to learn and innovate in the organization and the ability to reconfigure resources.

(1)Opportunity perception capability . Under the environment of market turmoil and technology update quickly, if enterprises want to gain and maintain competitive edge, they must be able to 
find opportunities and make a quick response. Therefore, the ability to recognize opportunities is one of the dimensions of dynamic capabilities. In 2007, Teece discussed dynamic capability in detail. The dynamic capabilities are divided into opportunity perception, opportunity exploitation and the ability to reconstruct. While opportunity perception can be divided into an ability to perceive opportunities and threats, to capture opportunities, as well as the ability to enhance, integrate, protect and reconstruct enterprise's dominant or recessive assets to maintain competitive edge. On the basis of Teece's theory, $\mathrm{O}$ 'reilly and Tushman set dimensions of dynamic capability as trichotomy. In China, through the studies on HuaLi and Galanz, LiXing Wang found that the behavior that enterprise adapted to environmental changes came from the ability of adequately known environment, including the characteristics of environmental law, environmental changes and analytical capability that the change of environment impacted on businesses.

(2)Resource acquisition capability. In order to survive, organizations need to resources, but organizations often do not produce these resources. Organizations must interact with the environmental factors that they depend on. Eisenhardt and Martin, from the perspective of organization and strategy divide dynamic capabilities into integration capabilities, restruction capability, ability to obtain and release. Zhu Binyu made the companies of traditional industry cluster in the Pearl River Delta as the research object to explore the influence factors and path of cluster enterprise technology innovation from the resource dependence theory. The model of absorptive capacity of resources and technology innovation performance was constructed.
(3) Organizational learning ability. Luo Min and Liu Yong Jun sum up the theory of dynamic capabilities and used the method of fuzzy clustering analysis to study the concept of dynamic capabilities theory in the past 10 years. They pointed out that the absorption of organizational learning capability had different and complementary four aspects: acquisition, internalization, conversion, and utilization. They thought that the four secondary elements were the core of the manufacturer to produce competitive edge.

(4)Integration restruction capability. Teece and Pisano divided dynamic capability into adaptability, integration and reconstruction ability. Eisenhardt and Martin divided dynamic capability into integration capabilities, restruction capability, ability to obtain and release from the angle of organization and the strategy. From the angle of concepts of dynamic capabilities and innovative performance, ShenDian Rong and WangChen made sure the dimension of dynamic capabilities. they thought that the capacity of absorptive organizational learning is the converter between external knowledge and enterprise's technology innovation performance. By the ability to absorb and learn a lot of knowledge, the organization can improve the performance of technological innovation, in turn technology innovation and performance improvement can increase the absorptive capacity of the enterprise by increasing the accumulation of knowledge.

In general, combing the literature can find that most of the scholars carry out the corresponding study from the aspects of the composition of dynamic capabilities. Due to the quality of measurement directly affects the effect of hypothesis test, so they should be determined objectively and scientifically. In a word, we apply the methods such as 
literature research and questionnaire survey to conduct exploratory analysis, and then we use spss16.0 and AMOS7.0 for statistical software analysis, finally establish reasonable measurement model of enterprise's dynamic ability.

\begin{tabular}{|c|c|c|c|c|c|}
\hline \multicolumn{6}{|c|}{ Table 1. Exploratory factor analysis } \\
\hline Variable & ItemI & \multicolumn{4}{|c|}{ factor score } \\
\hline \multirow{3}{*}{$\begin{array}{l}\text { Opportunity } \\
\text { perception }\end{array}$} & artareness to industry nule & .794 & .018 & .012 & .128 \\
\hline & $\begin{array}{c}\text { coguition in changed environment and } \\
\text { make plan }\end{array}$ & .806 & .078 & .042 & .000 \\
\hline & $\begin{array}{l}\text { communicate with enterprise and } \\
\text { stakelodolders }\end{array}$ & .768 & .165 & .067 & .078 \\
\hline \multirow{3}{*}{$\begin{array}{l}\text { Resoullce } \\
\text { acquisition }\end{array}$} & resoucces of low cost & .182 & .698 & .105 & .031 \\
\hline & fast access to resounces & .050 & .858 & .018 & .013 \\
\hline & $\begin{array}{l}\text { according to the enviromimental change } \\
\text { access to critical resources }\end{array}$ & .055 & .808 & .138 & .061 \\
\hline \multirow{3}{*}{$\begin{array}{l}\text { Organiluation } \\
\text { learning }\end{array}$} & attention and commitment to study & .132 & .003 & .048 & .773 \\
\hline & establish and share the vision & .180 & .092 & .112 & .759 \\
\hline & encourage enterprise open and innovation & .168 & .007 & .076 & .762 \\
\hline \multirow{3}{*}{$\begin{array}{l}\text { Integeration } \\
\text { resstruction }\end{array}$} & inter-departmentalal coordination & .155 & .113 & .771 & .120 \\
\hline & solve common problems & .035 & .118 & .741 & .006 \\
\hline & establish operational strategy & .057 & .006 & .817 & .125 \\
\hline
\end{tabular}

\section{Data and Research methods}

To verify the above theory model, this article adopts the form of the questionnaire survey to further test and analysis the structure dimension of dynamic capability. On the basis of the predecessors' theory research, we design preliminary questionnaire. The distributed objects mainly include the people who work in advertising, animation and computer software and other industries in creative industry gathering area in Tianjin. The methods of questionnaire distribution and recovery include kind questionnaire and email. We distribute 200 questionnaires, and take back 157 questionnaires. The recovery is $78.5 \%$. Excluding invalid questionnaires, we get 132 effective questionnaires and effective rate is $66 \%$.
In the design of questionnaire, the items and measurement variables adopt Likert 5 scale, including strongly agree, agree, not necessarily, disagree and strongly disagree. We require participants to show their attitude that he agrees or not. On scale design, opportunity perception includes awareness to industry rule, cognition in changed environment and making plan to communicate with enterprise and stakeholders. Resource acquisition ability includes three dimensions. First it is resources of low cost, fast access to resources and according to the environmental change access to critical resources. Next Organization learning ability is measured from three aspects including attention and commitment to study, establishing and sharing the vision and encouraging enterprise open and innovation. The last one item revision of integration restruction capability can be divided into inter-departmental coordination, solving common problems, and establishing operational strategy. This article use Crobanch's $\alpha$ to assess the reliability of the scale, the reliability of item is 0.850 and is more than the acceptable level of 0.7 through the test.

In the design of questionnaire, we define dynamic capabilities and set the measurement indicators according to the previous literature. Make appropriate modified with experts and enterprise managers in the process of questionnaire design. In addition, in order to guarantee the validity of the request, we conduct exploratory factor analysis in the opportunity perception, resource acquisition, organizational learning ability and integration restruction capability to further verify the questionnaire's construct validity. KMO test and Bartlett test results is 0.86 greater than 0.5 of the standard which is suitable for factor analysis. We get four factors after principal component analysis, 
namely the opportunity perception, resource acquisition, organizational learning ability and integration restruction capability. There is no cross load phenomenon, and each item of the ultimate load value is more than 0.5 standard. These indicate that they have good internal structure and high construct validity.

Using statistical software AMOS7.0 to inspect structural equation, in which the $\chi^{2} / \mathrm{df}$ is 1.288 , RMSE is 0.045 , AGFI is 0.892 , NFI is 0.795 , IFI is 0.946 , CFI is 0.941 .The model of goodness-of-fit indexes reach the standard normally, model and the data gets a good fitting results.

\begin{tabular}{c|c|c|c|c|c}
\multicolumn{7}{c}{ Table 2. Goodness of fit } \\
\hline Model & RMSEA & AGFI & IFI & $\begin{array}{c}\text { NFI } \\
\text { Delta1 }\end{array}$ & CFI \\
& & & & & \\
Default model & .045 & .892 & .946 & .795 & .941 \\
Independence model & .159 & & 1.000 & 1.000 & 1.000 \\
& & & .000 & .000 & .000 \\
\hline
\end{tabular}

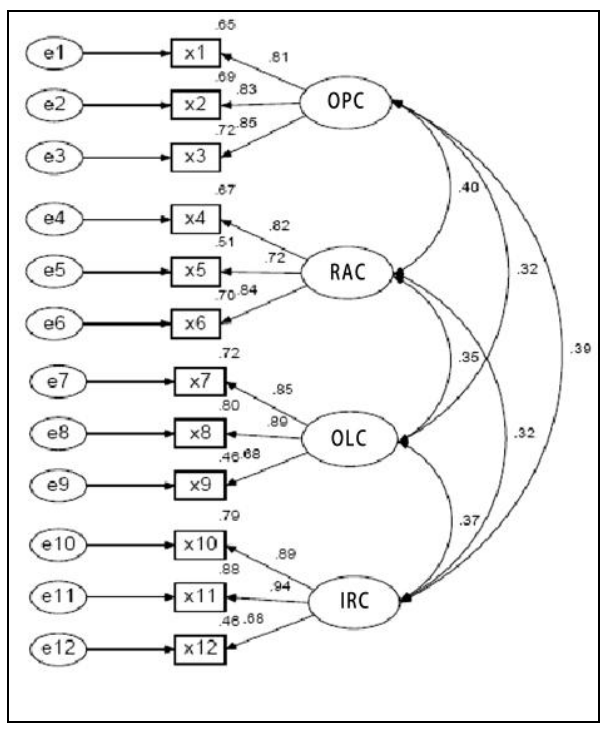

Fig. 1: Factor analysis results.

As shown in the figure 1, the hypothetical model contains 12 items, in which from 1 to 3 belongs to the factor of opportunity perception, from 4 to 6 belongs to the factor of resources acquisition, from 7 to 9 belongs to the factor of organization learning ability, from 10 to 12 belongs to factor of integration restruction capability. The load value of each item index among the factors is above 0.65 . Therefore, this article put forward four factors of the dynamic capability of model is verified.

\section{Conclusion}

This article uses empirical research to discuss the components of the dimension of the dynamic capabilities. Data analysis shows that dynamic capabilities include opportunity perception, resource acquisition, organizational learning ability and integrate restruction capability and factors and indicators are significantly positive correlation. The study of relationship between dimensions of dynamic capabilities formation and dimensions provides a powerful theoretical support when enterprises cultivate and develop dynamic capability in the process of the production and business operation. Business is based on its own core competence, can get through the organization of internal staff share learning, inter-departmental collaboration, the outside of the organization of resources effective acquisition, rapid response to the environment, and knowledge sharing to enhance the enterprise the competitive edge and ability to cope with risks.

Although this article conducts preliminary explore to the enterprise's dynamic ability dimension and measurement on the basis of the combination of qualitative research and quantitative research, there are still insufficient. Sample data collected is limited. We just select the creative cluster of industries and enterprises in Tianjin. If 
we can increase the area of samples, the result is more applicability. This article only discusses the dynamic capability of dimension problem, as for the source and function of dynamic capability also need further study.

\section{Acknowledgement}

The work was supported by the Art Scientific Research Planning of Tianjin(E12063)and the Philosophy and Social Sciences Research Planning of Tianjin(TJYYWT10-33).

\section{References}

[1]Teece .D , and Pisano .G , "The dynamic capabilities of firms: An introduction.Industrial and Corporate Change",vol.3,no.3,pp.53-556,1994.

[2]Teece.DJ,"Explicating dynamic capabilities: The nature and microfoundations of sustainable enterprises performance", Strategic Management vol.13,no.28,pp.1319-1350,2007.

[3]O'Reilly.CA,

Tushman. M,“ Ambidexterity as a dynamic capability: Resolving the innovator's dilemma", Research in Organizational Behavior,vol.1,no.28,pp.185 206,2008.

[4]Eisenhardt.KM, Marin.JA ,"Dynamic capabilities: What are they?", Strategic Management Journal,vol.11,no,21,pp.1105 1121,2000 .

[5]Wu.LY, "Applicability of the resource - based and dynamic - capability views under environmental volatility", Journal of Business Research, vol.1,no.63,pp27-31,2010.

[6]Drnevich.PL, Kriauciunas,AP, "Clarifying the conditions and limits of the contributions of ordinary and dynamic capabilities to relative firm performance",Strategic Management Journal, vol.2,no.32,pp.254 $279,2011$. 